\title{
Blunt Renal Trauma
}

\author{
Brian G. A. Dalton ${ }^{1} \quad$ Jeff J. Dehmer ${ }^{1}$ Sohail R. Shah ${ }^{1}$ \\ 1 Department of Surgery, Children's Mercy Hospital, Kansas City, \\ Missouri, United States \\ Address for correspondence Sohail R. Shah, MD, MSHA, Department \\ of Surgery, Children's Mercy Hospital and Clinics, 2401 Gillham Road, \\ J Pediatr Intensive Care 2015;4:16-20. \\ Kansas City, MO 64108, United States \\ (e-mail: sohailshahmd@gmail.com).
}
Abstract Keywords
- angioembolization
- blunt renal trauma
- kidney
- nonoperative management
- pediatrics

The pediatric patient is especially prone to blunt renal trauma due to the size and location of pediatric kidneys. No clear guidelines have been established for the management of these injuries in children to achieve the highest rate of renal salvage with low morbidity. Wide-ranging literature exists on this subject, but consists of vastly different management strategies. This review is written to summarize the different approaches to blunt renal trauma and highlight opportunities for further research.

\section{Introduction}

In the pediatric patient, traumatic injury is the leading cause of death and blunt trauma is the most common mechanism of injury. Renal injuries account for 8 to $12 \%$ of pediatric blunt abdominal injuries. Children, more so than adults, are prone to sustain major renal injury due to blunt trauma given the relatively large size of pediatric kidneys and decreased protection in children. ${ }^{1-3}$

The primary goal after blunt renal trauma is to preserve renal function. However, no well established guidelines best suited to accomplish this goal have been published in the pediatric literature. Variable strategies for mode of imaging, role of angioembolization (AE), intensive care unit (ICU) observation, length of bed rest, relevance of hematuria, role of ureteral stenting, the incidence of sequelae, and follow-up imaging have been employed. A review of current evidence is presented here to show current strategies for management of blunt renal trauma in the pediatric population.

\section{Diagnosis}

Hematuria typically plays a major role in the decision to obtain imaging in adult patients with blunt abdominal trauma. Some have proposed that in the presence of microscopic hematuria, hemodynamic stability, and low suspicion of major intra-abdominal injury, imaging may be unnecessary. ${ }^{4}$

received

October 5, 2014 accepted after revision November 10, 2014 Pablo Aguayo, MD

Conversely, it has been suggested that imaging in adult patients is only necessary in the setting of gross hematuria, microscopic hematuria with hemodynamic instability, high index of suspicion for abdominal injury, or significant deceleration injury. ${ }^{5}$

Similar criteria have previously been proposed to direct imaging in the pediatric population. ${ }^{6-8}$ However, children tend to have a greater physiologic reserve than adults, and may not demonstrate early hypotension despite significant renal injury. Using hypotension and hematuria as screening criteria for imaging has been shown to miss several severe renal injuries. ${ }^{8,9}$ Level of hematuria has also been examined as a screening tool for imaging in renal trauma. For instance, some studies have designated a low yield for the use of intravenous pyelography if there are less than 100 red blood cells per high power field. ${ }^{10}$ Yet other series have designated 20 or 50 red blood cells as the cutoff for imaging. ${ }^{11,12}$ In the pediatric population; however, it is important to realize that hematuria may be the presenting symptom of a congenital anomaly or highly vascular neoplasm, such as Wilms tumor. In fact, undiagnosed renal anomalies can occur in up to $19 \%$ of children undergoing computed tomography (CT) of the abdomen for trauma. ${ }^{13}$ Given these possible diagnoses and the consequences for missed injury, we currently recommend imaging for any child with hematuria after trauma.

Historically, intravenous pyelography was the standard method of imaging in suspected blunt renal trauma. This

Copyright $\odot 2015$ by Georg Thieme Verlag KG, Stuttgart - New York
DOI http://dx.doi.org/ 10.1055/s-0035-1554984. ISSN 2146-4618. 
has largely been supplanted by ultrasound and CT over the last two decades. Ultrasound may be useful as screening modality in patients that are hemodynamically unstable. However, the use of ultrasound as a diagnostic study can lead to missed diagnoses with regards to parenchymal kidney injury or collecting system injuries. CT, on the other hand, has been shown to have a negative predictive value of as high as $99.8 \%$ for all intra-abdominal injuries and is a superior method for diagnosing renal injuries in the pediatric population. $^{14-16}$ Furthermore, select findings on CT have been shown to help predict the need for intervention in renal trauma. ${ }^{17}$ For these reasons, in a pediatric patient with concern for intra-abdominal injury and gross or microscopic hematuria, CT should be the initial imaging modality of choice. The American Association for the Surgery of Trauma injury scoring scale is based on CT findings and is shown in - Table 1.

Given the concern for future malignant potential, increased cost, and noting that many renal injuries do not require any intervention, efforts to reduce exposure to unnecessary radiation is common in many pediatric centers. Scoring systems and algorithms to predict intra-abdominal injury in children has recently been utilized to safely decrease radiation exposure in the pediatric population while minimizing the risk of missed injuries. ${ }^{18-20}$ Although no single algorithm has been prospectively validated, adoption of set guidelines at large trauma centers has led to a decrease in unnecessary radiation exposure in children.

\section{Management}

\section{Operative Intervention}

In the pediatric population, the vast majority of blunt renal trauma is managed nonoperatively, ${ }^{21-28}$ with a renal preservation rate of up to $99 \%{ }^{23-25}$ While it has generally been accepted that most grades I to III injuries can be managed safely with nonoperative intervention, high-grade renal injuries (grades IV-V) secondary to blunt trauma remain an area of controversial management. In a recent meta-analysis of grade IV renal injuries $72 \%$ were successfully managed non- operatively. Only $19 \%$ of the patients in this study required an intervention and of those 95 patients, only 3 required nephrectomy. ${ }^{28}$ A 20 -year review of pediatric blunt renal trauma revealed only 8 of 164 (6.3\%) patients required surgical intervention for renal trauma, all 8 of which were grade IV or V. In a separate review, considering only high-grade (IV-V) renal injuries, only $16.3 \%$ of patients required surgical intervention. Only two of these patients required immediate intervention. ${ }^{26}$ Given these findings immediate operative intervention for pediatric renal trauma should be reserved for the rare case of hemodynamic instability, even with grade IV or V renal injuries. Indications for delayed intervention include continued bleeding, continued urinary extravasation, and recurrent infection.

\section{Angioembolization}

$\mathrm{AE}$ as a treatment for bleeding solid organ injury in blunt trauma has been used for control of hemorrhage and organ preservation in adults since the $1990 \mathrm{~s} .{ }^{29}$ The role of $\mathrm{AE}$ in the pediatric population is less well defined. In adults the blush sign or contrast extravasation (CE), indicating ongoing arterial hemorrhage, has been shown to predict nonoperative failure and is an indication for angiography in many centers. ${ }^{30}$ This finding has been replicated specifically in adult renal trauma. ${ }^{31}$ However, in a series of 86 pediatric abdominal CT available for review after blunt abdominal trauma, 6 were found to have CE associated with a splenic injury. Only one of six children required surgical intervention. In another series of 123 pediatric patients with splenic injury, 8 were found to have $\mathrm{CE}$ on CT. None of these patients required intervention and patients with $\mathrm{CE}$ did not have a higher transfusion requirement or mortality. ${ }^{32}$ In contrast to this, a metaanalysis of pediatric spleen and liver injury revealed a lower failure rate of nonoperative management when $\mathrm{AE}$ was used as a treatment option. ${ }^{33}$ No large series addressing CE in renal trauma in children has been published. However, data on the use of $\mathrm{AE}$ to treat renal trauma in the pediatric population has been published. In a review of 127 pediatric trauma patients, Kiankhooy et $\mathrm{al}^{34}$ describe AE for seven solid organ injuries, three of which were renal injuries. All three patients had

Table 1 The American Association for the Surgery of Trauma injury scoring scale kidney injury

\begin{tabular}{|l|l|l|}
\hline Grade & Type of injury & Description \\
\hline \multirow{2}{*}{ I } & Contusion & Microscopic or gross hematuria, urologic studies normal \\
\cline { 2 - 3 } & Hematoma & Subcapsular, nonexpanding without parenchymal laceration \\
\hline \multirow{2}{*}{ III } & Hematoma & Nonexpanding perirenal hematoma confined to retroperitoneum \\
\cline { 2 - 3 } & Laceration & $<1.0 \mathrm{~cm}$ parenchymal of renal cortex without urinary extravasation \\
\hline IV & Laceration & $\begin{array}{l}>1.0 \mathrm{~cm} \text { parenchymal depth of renal cortex without collecting } \\
\text { system rupture or urinary extravasation }\end{array}$ \\
\hline \multirow{2}{*}{ V } & Laceration & Parenchymal laceration extending through renal cortex, medulla, and collecting system \\
\cline { 2 - 3 } & Vascular & Main renal artery or vein injury with contained hemorrhage \\
\cline { 2 - 3 } & Laceration & Completed shattered kidney \\
\cline { 2 - 3 } & Vascular & Avulsion of renal hilum, which devascularizes kidney \\
\hline
\end{tabular}


sustained grade IV injury and had declining hemoglobin levels despite transfusion. Renal preservation was successful in all three cases without long-term hypertension or renal insufficiency. The role of AE in children for blunt renal trauma is an area that needs further research; however, in centers with the available resources and experience, it has become a viable alternative to surgical intervention.

\section{Nonoperative Management}

Clearly, the current literature reflects that the vast majority of blunt renal trauma can be managed, nonoperatively, with successful nonoperative rates well over $90 \%{ }^{21-28,35}$ Nonoperative management guidelines for spleen and liver injuries have been articulated. ${ }^{36}$ Certain aspects of these guidelines have been challenged recently, ${ }^{37,38}$ but these guidelines are often extended to patients with blunt renal injury. These guidelines may not be directly applicable to renal trauma as spleen and liver being intra-abdominal organs have a greater potential space for adjacent blood loss. On the other hand, the kidneys are encapsulated within Gerota fascia within the retroperitoneum so the chance for life-threatening bleeding is theoretically lower. Our management protocol allows for ambulation when the patient is comfortable to do so. The presence of hematuria, while monitoring, is not a barrier to ambulation or discharge. A urinary catheter is not routinely placed unless the patient has difficulty in urinating. Antibiotics, urine culture, or urology consults are not routinely utilized. Patients are discharged when tolerating a regular diet and pain is controlled by oral pain medications. ${ }^{35}$

\section{Intensive Care Unit Observation}

No consensus exists on the recommended length of ICU stay of blunt renal trauma, even in high-grade injuries. While there are no published guidelines in this area, the majority of series on pediatric blunt renal trauma do not report level of care with respect to length of stay. ${ }^{24,28,35}$ In a series of 95 patients, the authors utilized a strategy of 24-hour admission to the ICU with at least 3 days in the hospital. ${ }^{39}$ While this strategy produced a high rate of renal preservation (98.9\%) and successful nonoperative management $(94.7 \%)$, they failed to validate the length of stay as necessary. This approach was most likely borrowed from published guidelines on the management of pediatric liver and spleen injury. ${ }^{36}$ Currently, there is strong evidence that the mandatory ICU stay is not necessary for stable patients with liver or spleen injury. ${ }^{37,38}$ Given the high rate of renal salvage, the success of nonoperative management and retroperitoneal position within Gerota fascia of the kidneys, ICU admission for their renal injury is unnecessary in stable patients. Our current practice is to admit patients with blunt renal trauma to general observation unless the patient is hemodynamically unstable or has concomitant injuries mandating ICU admission. Completely asymptomatic patients with low-grade injury who are able to ambulate are discharged from the emergency department and followed up according to our prospective protocol.

\section{Bed Rest}

The initial report using bed rest as a treatment option used strict in-hospital bed rest of 5 to 7 days and an additional 10 days to 2 weeks of rest at home. ${ }^{40}$ The American Pediatric Surgery Association guidelines on bed rest for solid organ injury were proposed to be grade of injury plus 1 additional day. ${ }^{36}$ A more recent series used gradual advancement of activity during a 4-day hospital stay. ${ }^{39}$ Other studies have used a resolution of hematuria either gross or microscopic as a marker to guide length of bed rest. ${ }^{41,42}$ A recent prospective trial attempted to address both issues of bed rest and hematuria as an indication for advancement to normal activity. A series of 70 patients were enrolled in a protocol that allowed for ambulation when the patient was comfortable doing so, and the presence of hematuria was not used to limit activity. Mean time to ambulation was 1.5 days and mean length of stay was 2.9 days. No patients developed delayed bleeding or required subsequent intervention after initial stabilization. Renal salvage rates with this approach were 98.6\%. The success rate of this nonoperative approach was $97.2 \%$. Hematuria was monitored at follow-up, but its presence seemed to have no effect on at least early outcomes. ${ }^{35}$ Given the findings of this trial, we currently do not restrict patients to bed rest if they are comfortable enough to ambulate and we do not use hematuria to guide hospital length of stay.

\section{Ureteral Stenting}

Collecting system injuries present an interesting issue in the era of nonoperative management of high-grade renal injuries. Internal drainage with a stent has been shown to produce good results by providing a low-pressure system for the drainage of the collecting system. ${ }^{39,43,44}$ The question of patient selection in stenting, collecting system injury remains unsolved. A recent study found that medial CE from the collecting system on the initial CT was associated with a need for intervention. ${ }^{17}$ In a study of high-grade injuries with collecting system involvement, $80 \%$ healed without the intervention and 20\% underwent ureteral stent placement for continued CE. ${ }^{44}$ In a prospective trial, 9 of 70 patients underwent follow-up ultrasound after concern for collecting system injury at initial CT. All patients were found to have a normal sonographic examination. ${ }^{35}$ Complications of stent placement (infection, iatrogenic perforation, ureteral obstruction) are rare but must be balanced against the long-term goal of renal preservation. ${ }^{44}$ Symptomatic urinomas and continued CE after 2 weeks appear to be the most often cited indications for ureteral stenting after high-grade blunt renal trauma. ${ }^{39,44}$

\section{Hypertension}

The precise rate of postrenal injury, hypertension is difficult to define due to lack of comprehensive follow-up in these patients. Estimates range from 0 to $7.5 \%{ }^{21}$ Annual blood pressure measurements have been recommended for monitoring. ${ }^{39}$ A prospective 3-year evaluation of patients that sustain blunt renal injury is currently underway to elucidate the true incidence and severity of postinjury hypertension. 


\section{Follow-Up}

A definitive imaging follow-up regimen after blunt renal injury is not well documented. Some authors suggest a urologic workup at 1-year posttrauma. ${ }^{3}$ More recently, it has been suggested that no routine follow-up imaging is necessary after low-grade injury (I-III). Some authors recommend reimaging in 24 to 36 hours for high-grade injuries after the trauma as it may influence the timing and need for intervention. $^{39,45} \mathrm{~A}$ recent study in the adult population revealed that in a series of 105 patients (24 high-grade injuries) only 5 patients developed complications and all were symptomatic. ${ }^{46}$ This certainly calls into question the need for routine imaging in blunt renal trauma. Any question of renal function can be evaluated by a technetium-99m dimercaptosuccinic acid scanning. At our institution, we currently obtain renal ultrasounds at 2 to 6 months postinjury in patients with urinary extravasation or injuries concerning for collecting system stricture on initial CT, otherwise no repeat imaging is recommended. All patients with blunt renal injury at our institution are followed up with urinalysis 2 to 4 weeks after discharge, and repeated as indicated. Follow-up imaging is obtained for suspected urinary extravasation. Blood pressure is monitored twice yearly for 3 years. ${ }^{35}$

\section{References}

1 Brown SL, Elder JS, Spirnak JP. Are pediatric patients more susceptible to major renal injury from blunt trauma? A comparative study. J Urol 1998;160(1):138-140

2 Kuzmarov IW, Morehouse DD, Gibson S. Blunt renal trauma in the pediatric population: a retrospective study. J Urol 1981;126(5): 648-649

3 Smith MJ, Seidel RF, Bonacarti AF. Accident trauma to the kidneys in children. J Urol 1966;96(6):845-847

4 Miller KS, McAninch JW. Radiographic assessment of renal trauma: our 15-year experience. J Urol 1995;154(2 Pt 1):352-355

5 Heyns CF. Renal trauma: indications for imaging and surgical exploration. BJU Int 2004;93(8):1165-1170

6 Santucci RA, Langenburg SE, Zachareas MJ. Traumatic hematuria in children can be evaluated as in adults. J Urol 2004;171(2 Pt 1): 822-825

7 Smith JK, Kenney PJ. Imaging of renal trauma. Radiol Clin North Am 2003;41(5):1019-1035

8 Abou-Jaoude WA, Sugarman JM, Fallat ME, Casale AJ. Indicators of genitourinary tract injury or anomaly in cases of pediatric blunt trauma. J Pediatr Surg 1996;31(1):86-89, discussion 90

9 Cass AS, Luxenberg M, Gleich P, Smith CS. Clinical indications for radiographic evaluation of blunt renal trauma. J Urol 1986;136(2): 370-371

10 Hashmi A, Klassen T. Correlation between urinalysis and intravenous pyelography in pediatric abdominal trauma. J Emerg Med 1995;13(2):255-258

11 Fleisher G. Prospective evaluation of selective criteria for imaging among children with suspected blunt renal trauma. Pediatr Emerg Care 1989;5(1):8-11

12 Perez-Brayfield MR, Gatti JM, Smith EA, et al. Blunt traumatic hematuria in children. Is a simplified algorithm justified? J Urol 2002;167(6):2543-2546, discussion 2546-2547

13 Schmidlin FR, Iselin CE, Naimi A, et al. The higher injury risk of abnormal kidneys in blunt renal trauma. Scand J Urol Nephrol 1998;32(6):388-392
14 Brown SL, Haas C, Dinchman KH, Elder JS, Spirnak JP. Radiologic evaluation of pediatric blunt renal trauma in patients with microscopic hematuria. World J Surg 2001;25(12):1557-1560

15 Chowdhary SK, Pimpalwar A, Narasimhan KL, Katariya S, Rao KL. Blunt injury of the abdomen: a plea for CT. Pediatr Radiol 2000; 30(11):798-800

16 Hom J. The risk of intra-abdominal injuries in pediatric patients with stable blunt abdominal trauma and negative abdominal computed tomography. Acad Emerg Med 2010;17(5):469-475

17 Bartley JM, Santucci RA. Computed tomography findings in patients with pediatric blunt renal trauma in whom expectant (nonoperative) management failed. Urology 2012;80(6): 1338-1343

18 Streck CJ Jr, Jewett BM, Wahlquist AH, Gutierrez PS, Russell WS. Evaluation for intra-abdominal injury in children after blunt torso trauma: can we reduce unnecessary abdominal computed tomography by utilizing a clinical prediction model? J Trauma Acute Care Surg 2012;73(2):371-376, discussion 376

19 de Jong WJ, Stoepker L, Nellensteijn DR, Groen H, El Moumni M, Hulscher JB. External validation of the Blunt Abdominal Trauma in Children (BATiC) score: ruling out significant abdominal injury in children. J Trauma Acute Care Surg 2014;76(5):1282-1287

20 Karam O, Sanchez O, Chardot C, La Scala G. Blunt abdominal trauma in children: a score to predict the absence of organ injury. J Pediatr 2009;154(6):912-917

21 Fraser JD, Aguayo P, Ostlie DJ, St Peter SD. Review of the evidence on the management of blunt renal trauma in pediatric patients. Pediatr Surg Int 2009;25(2):125-132

22 Wessel LM, Scholz S, Jester I, et al. Management of kidney injuries in children with blunt abdominal trauma. J Pediatr Surg 2000; 35(9):1326-1330

23 Aguayo P, Fraser JD, Sharp S, Holcomb GW III, Ostlie DJ, St Peter SD. Nonoperative management of blunt renal injury: a need for further study. J Pediatr Surg 2010;45(6):1311-1314

24 Buckley JC, McAninch JW. Pediatric renal injuries: management guidelines from a 25-year experience. J Urol 2004;172(2): 687-690, discussion 690

25 Fitzgerald CL, Tran P, Burnell J, Broghammer JA, Santucci R. Instituting a conservative management protocol for pediatric blunt renal trauma: evaluation of a prospectively maintained patient registry. J Urol 2011;185(3):1058-1064

26 Henderson CG, Sedberry-Ross S, Pickard R, et al. Management of high grade renal trauma: 20-year experience at a pediatric level I trauma center. J Urol 2007;178(1):246-250, discussion 250

27 Nerli RB, Metgud T, Patil S, et al. Severe renal injuries in children following blunt abdominal trauma: selective management and outcome. Pediatr Surg Int 2011;27(11):1213-1216

28 Umbreit EC, Routh JC, Husmann DA. Nonoperative management of nonvascular grade IV blunt renal trauma in children: metaanalysis and systematic review. Urology 2009;74(3):579-582

29 Dent D, Alsabrook G, Erickson BA, et al. Blunt splenic injuries: high nonoperative management rate can be achieved with selective embolization. J Trauma 2004;56(5):1063-1067

30 Olthof DC, Joosse P, van der Vlies CH, de Haan RJ, Goslings JC. Prognostic factors for failure of nonoperative management in adults with blunt splenic injury: a systematic review. J Trauma Acute Care Surg 2013;74(2):546-557

31 Nuss GR, Morey AF, Jenkins AC, et al. Radiographic predictors of need for angiographic embolization after traumatic renal injury. J Trauma 2009;67(3):578-582, discussion 582

32 Davies DA, Ein SH, Pearl R, et al. What is the significance of contrast "blush" in pediatric blunt splenic trauma? J Pediatr Surg 2010; 45(5):916-920

33 van der Vlies CH, Saltzherr TP, Wilde JC, van Delden OM, de Haan $\mathrm{RJ}$, Goslings JC. The failure rate of nonoperative management in children with splenic or liver injury with contrast blush on computed tomography: a systematic review. J Pediatr Surg 2010;45(5):1044-1049 
34 Kiankhooy A, Sartorelli KH, Vane DW, Bhave AD. Angiographic embolization is safe and effective therapy for blunt abdominal solid organ injury in children. J Trauma 2010;68(3):526-531

35 Graziano KD, Juang D, Notrica D, et al. Prospective observational study with an abbreviated protocol in the management of blunt renal injury in children. J Pediatr Surg 2014;49(1):198-200, discussion 200-201

36 Stylianos S; The APSA Trauma Committee. Evidence-based guidelines for resource utilization in children with isolated spleen or liver injury. J Pediatr Surg 2000;35(2):164-167, discussion 167-169

37 St Peter SD, Aguayo P, Juang D, et al. Follow up of prospective validation of an abbreviated bedrest protocol in the management of blunt spleen and liver injury in children. J Pediatr Surg 2013; 48(12):2437-2441

38 McVay MR, Kokoska ER, Jackson RJ, Smith SD. Throwing out the "grade" book: management of isolated spleen and liver injury based on hemodynamic status. J Pediatr Surg 2008;43(6):1072-1076

39 Nance ML, Lutz N, Carr MC, Canning DA, Stafford PW. Blunt renal injuries in children can be managed nonoperatively: outcome in a consecutive series of patients. J Trauma 2004;57(3):474-478, discussion 478
40 Ahmed S, Morris LL. Renal parenchymal injuries secondary to blunt abdominal trauma in childhood: a 10-year review. Br J Urol 1982;54(5):470-477

41 Margenthaler JA, Weber TR, Keller MS. Blunt renal trauma in children: experience with conservative management at a pediatric trauma center. J Trauma 2002;52(5):928-932

42 Broghammer JA, Langenburg SE, Smith SJ, Santucci RA. Pediatric blunt renal trauma: its conservative management and patterns of associated injuries. Urology 2006;67(4):823-827

43 Philpott JM, Nance ML, Carr MC, Canning DA, Stafford PW. Ureteral stenting in the management of urinoma after severe blunt renal trauma in children. J Pediatr Surg 2003;38(7): 1096-1098

44 Rogers CG, Knight V, MacUra KJ, Ziegfeld S, Paidas CN, Mathews RI. High-grade renal injuries in children-is conservative management possible? Urology 2004;64(3):574-579

45 Malcolm JB, Derweesh IH, Mehrazin R, et al. Nonoperative management of blunt renal trauma: is routine early follow-up imaging necessary? BMC Urol 2008;8:11

46 Breen KJ, Sweeney P, Nicholson PJ, Kiely EA, O’Brien MF. Adult blunt renal trauma: routine follow-up imaging is excessive. Urology 2014;84(1):62-67 